\title{
Diagnostic Performance of PET and Perfusion-Weighted Imaging in Differentiating Tumor Recurrence or Progression from Radiation Necrosis in Posttreatment Gliomas: A Review of Literature
}

\author{
(D) N. Soni, (D) M. Ora, (D) N. Mohindra, (D) Y. Menda, and (D) B. Bathla
}

\begin{abstract}
SUMMARY: Tumor resection followed by chemoradiation remains the current criterion standard treatment for high-grade gliomas. Regardless of aggressive treatment, tumor recurrence and radiation necrosis are 2 different outcomes. Differentiation of tumor recurrence from radiation necrosis remains a critical problem in these patients because of considerable overlap in clinical and imaging presentations. Contrast-enhanced MR imaging is the universal imaging technique for diagnosis, treatment evaluation, and detection of recurrence of high-grade gliomas. PWI and PET with novel radiotracers have an evolving role for monitoring treatment response in high-grade gliomas. In the literature, there is no clear consensus on the superiority of either technique or their complementary information. This review aims to elucidate the diagnostic performance of individual and combined use of functional (PWI) and metabolic (PET) imaging modalities to distinguish recurrence from posttreatment changes in gliomas.
\end{abstract}

\begin{abstract}
ABBREVIATIONS: AAT = amino acid tracer; ASL = arterial spin-labeling; AUC = area under the curve; "C-MET $={ }^{11} \mathrm{C}-\mathrm{methionine}$; DCE $=$ dynamic contrastenhanced; FDOPA $=6$ - $\left[{ }^{18} \mathrm{~F}\right]$ fluoro-L-dopa; FET $=\left[{ }^{18} \mathrm{~F}\right]$ fluoroethyl-L-tyrosine; FLT $={ }^{18} \mathrm{~F}$-fluorothymidine; HGG $=$ high-grade glioma; $K^{\text {trans }}=$ volume transfer constant; $\mathrm{rCBV}=$ relative cerebral blood volume; $\mathrm{RN}=$ radiation necrosis; $\mathrm{TBR}=$ tumor-to-background ratio; $\mathrm{TR}=$ tumor recurrence; $\mathrm{Ve}=$ volume of tissue; $\mathrm{Vp}=$ plasma volume
\end{abstract}

G liomas are primary brain tumors with an incidence of 5-6 per 100,000 population. Glioblastoma is the most common and aggressive subtype with a median survival period of $<15$ months and a 5-year survival rate of $<10 \%{ }^{1}$ The current criterion standard treatment for high-grade gliomas (HGGs) is maximum tumor resection followed by radiation therapy with concurrent and adjuvant temozolomide-based chemotherapy, which has shown improved survival. Despite advances in imaging and multidisciplinary treatment, glioblastoma carries a dismal prognosis. Chemoradiation may induce new enhancement and edema that may mimic tumor recurrence (TR) or progression on follow-up imaging. TR is inevitable after a median survival time of 32-36 weeks. ${ }^{2}$ Radiation necrosis (RN) may also manifest as new or increased enhancement caused by disruption of the BBB

Received January 8, 2020; accepted after revision May 29.

From the Department of Radiology (N.S., Y.M., G.B.), University of lowa Hospitals and Clinics, lowa City, lowa; and Department of Radiodiagnosis (M.O., N.M.), Sanjay Gandhi Post Graduate Institute of Medical Sciences, Institute of Nuclear Medicine, Lucknow, India.

Neetu Soni and Manish Ora share first authorship.

Please address correspondence to Neetu Soni, MD, Department of Nuclear Medicine, University of lowa Hospitals and Clinics, 200 Hawkins Dr, lowa City, IA 52242; e-mail: neetu-soni@uiowa.edu; @NeetuSo27437480

- Indicates open access to non-subscribers at www.ajnr.org

Indicates article with supplemental on-line tables.

http://dx.doi.org/10.3174/ajnr.A6685 from detrimental effects of radiation on the surrounding healthy tissue. RN usually manifests 3-12 months after radiation therapy with an incidence of $3 \%-24 \%$ depending on radiation dose. ${ }^{3}$ Apart from RN, pseudoprogression and pseudoresponse are 2 new posttreatment entities that have been recognized during follow-up. Pseudoprogression may constitute an overresponse to effective treatment with a reported incidence of $10 \%-30 \%$ and usually occurs within the first 3 months after completing radiation therapy with or without temozolomide. Pseudoresponse refers to a transient rapid decrease in lesion enhancement and surrounding edema after antiangiogenic treatment (ie, bevacizumab) by normalizing the BBB and mimicking favorable tumor response while the actual tumor remains viable or progresses. ${ }^{2,4,5}$

Contrast-enhanced MR imaging remains the primary imaging technique in HGG follow-up because of its widespread availability and excellent soft-tissue and contrast resolution. A recent meta-analysis of glioblastoma with enhancing lesions on posttreatment MR imaging revealed true progression in $60 \%$ and treatment-related changes in $36 \%$ of patients. ${ }^{6}$ Posttreatment evaluation is generally based on Response Assessment in NeuroOncology criteria that rely on clinical condition, lesion size, and enhancement. ${ }^{7}$ Recently, The Response Assessment in NeuroOncology working group recommended PET using radio-labeled amino acids as an additional tool in the diagnostic assessment of brain tumors. ${ }^{8}$ Differentiation of "tumor progression/recurrence" 
and "treatment-related changes" is still challenging, and to date, no single technique provides a reliable detection of glioma recurrence. Biopsy remains the criterion standard to give immediate therapy decisions compared with clinical follow-up. However, as an invasive procedure, it is associated with morbidity and mortality rates of $1 \%-5 \%$ and $0 \%-2.3 \%$, respectively. ${ }^{9}$ It is also important for pathologists to be aware of tumor heterogeneity while analyzing biopsy samples in these cases. ${ }^{5}$

There is no standard management for recurrent glioblastoma, and patients may undergo reoperation, re-radiation, or chemotherapy with progression-free survival and overall survival of 10 and 30 weeks, respectively. ${ }^{10}$ Thus, accurate and timely diagnosis of recurrent tumor is necessary to reduce the surgical risk and health care cost and improve the quality of life. Limitations of conventional imaging in evaluating posttreatment changes have encouraged the use of advanced MR imaging techniques (perfusion, diffusion-weighted, and spectroscopy) and PET imaging with novel radiopharmaceuticals. Both imaging modalities have their advantages and limitations at the expense of time and cost burden.

PWI is commonly used for the primary diagnosis and posttreatment glioma surveillance. The 3 most frequently used MR perfusion techniques are $\mathrm{T} 2{ }^{\star}$-based dynamic susceptibility contrast (DSC); T1-weighted dynamic contrast-enhanced (DCE), which uses exogenous contrast; and arterial spin-labeling (ASL) based on arterial endogenous tracer. ${ }^{11,12}$ Because PET is a functional technique, it may provide additional insight beyond MR imaging into the biology of gliomas, which may have a potential role in the noninvasive grading, tumor delineation, radiation therapy planning, and posttreatment response evaluation. ${ }^{13}$ Use of $\left[{ }^{18} \mathrm{~F}\right]$ FDG is widespread in clinical nuclear medicine and is of relatively low cost. Because of the low tracer uptake in gray matter, amino acid tracers (AATs) are very helpful in differentiating TR from treatment-induced changes. ${ }^{11} \mathrm{C}$-methionine $\left({ }^{11} \mathrm{C}\right.$-MET) is the most studied and validated AAT. ${ }^{8}$ With the advent of integrated PET/MR imaging in clinical practice, studies have shown a strong correlation between these 2 modalities by providing complete anatomic, functional, and metabolic information of tumors at a single point of time. This review summarizes the current role, limitations, and challenges of perfusion MR imaging and PET imaging to differentiate $\mathrm{TR}$ or progression from $\mathrm{RN}$ in gliomas.

\section{Literature Search}

We searched PubMed to collect relevant published articles (up to October 2019) aiming to provide independent or comparative results of these 2 imaging modalities in differentiating TR or progression from RN in gliomas. Eligible studied fulfilled the following criteria: 1) pathologically proved glioma (grades II-IV); 2) newly enhancing lesions on imaging, with diagnoses of TR or RN on PET, PWI, or both; 3) definitive diagnosis based on histopathology and/or clinical and imaging follow-up; 4) sample size $\geq 20$ for individual technique and $\geq 10$ for combined studies; and 5) full-text articles in English. We followed a nonquantitative approach and extracted the relevant information from each article.

\section{Perfusion-Weighted Imaging}

Parameters derived from perfusion MR imaging indirectly evaluate tumor neoangiogenesis by assessing blood volume, blood flow, and permeability. Whereas TR reflects hyperperfusion caused by associated neoangiogenesis, $\mathrm{RN}$ shows hypoperfusion caused by coagulative necrosis. DSC is the most widely used PWI because of the short acquisition time and widely available userfriendly postprocessing software. However, DSC has susceptibility artifacts and effects of contrast leakage. DCE provides better spatial resolution, is less prone to susceptibility artifacts, and evaluates both blood volume and permeability. However, the complex pharmacokinetic compartment models and nonavailability of user-friendly or vendor-based standardized software limit the use of DCE-PWI. Relative cerebral blood volume ( $\mathrm{rCBV}$ ) is the most validated perfusion parameter for evaluation of brain tumors that can be assessed both qualitatively and quantitatively. ${ }^{11,12}$ ASL is a noninvasive perfusion technique that uses magnetically labeled arterial blood as an endogenous tracer, so it is less prone to susceptibility artifacts. ASL provides absolute quantification of CBF that is reliable and reproducible and correlates with other perfusion techniques. ${ }^{11}$ Several studies have shown the usefulness of DSC, DCE, and ASL to distinguish TR from $\mathrm{RN}$ in gliomas (On-line Table 1). ${ }^{14-27}$

A few studies have compared DSC and DCE perfusion techniques for differentiating TR from RN (On-line Table 1). ${ }^{22,23,25} \mathrm{~A}$ recent meta-analysis including 28 articles demonstrated a pooled sensitivity and specificity of $90 \%$ and $88 \%$ for DSC and $89 \%$ and $85 \%$ for DCE, respectively. ${ }^{28}$ Another meta-analysis also verified similar results, with a pooled sensitivity and specificity of $87 \%$ and $86 \%$ for DSC and $92 \%$ and $85 \%$ for DCE, respectively. The study reported a wide range of optimal rCBV cutoff values (range, 0.71-3.7) to reliably distinguish TR from RN because of technical issues such as vascular leak. ${ }^{29}$ Kim et al, ${ }^{30}$ in their large retrospective study, reported the added value of either DSC or DCE-PWI to the routine MR imaging in significantly improving the prediction of recurrent glioblastoma. Using a mean rCBV threshold of 1.8 , Young et $\mathrm{al}^{15}$ found $100 \%$ sensitivity and $75 \%$ specificity in identifying TR. Nael et al $^{22}$ found $80 \%$ sensitivity and $92 \%$ specificity by using a mean rCBV threshold of 2.2. Di Costanzo et $\mathrm{al}^{16}$ also found significantly higher $\mathrm{rCBV}$ values in recurrent glioma than in $\mathrm{RN}$ and reported similar diagnostic accuracy $(86 \%)$ as in the literature. Wang et $\mathrm{al}^{18}$ used maximum rCBV instead of rCBV mean values and reported $62 \%$ sensitivity and $80 \%$ specificity at a cutoff of 4.4. In many cases, TR coexists with $\mathrm{RN}$, leading to overlap of the $\mathrm{rCBV}$ ratios. ${ }^{19}$ Blasel et $\mathrm{al}^{19}$ also reported superior diagnostic accuracy of maximum $\mathrm{rCBV}$ (sensitivity, 78\%; specificity, 86\%) compared with rCBVmean (sensitivity, 65\%; specificity, 71\%), which reflects tumor heterogeneity and regional perfusion differences.

A recent meta-analysis by van Dijken et $\mathrm{al}^{29}$ showed higher diagnostic accuracy of DCE compared with DSC, but another meta-analysis by Patel et al, ${ }^{28}$ showed equal diagnostic accuracy of both in differentiating TR from RN. DCE-derived parameters include volume transfer constant $\left(K^{\text {trans }}\right)$, extravascular extracellular space per unit volume of tissue (Ve), and plasma volume $(\mathrm{Vp}) .^{4,29}$ Yun et $\mathrm{al}^{21}$ found mean $K^{\text {trans }}$ as the most promising parameter in differentiating true progression from pseudo- 
progression (sensitivity, 59\%; specificity, 94\%) compared with Vp. On the contrary, Thomas et $\mathrm{al}^{20}$ found higher area under curve (AUC) for Vp compared with $K^{\text {trans }}$ in differentiating pseudoprogression (Vp cutoff, $<3.7$; sensitivity, 85\%; specificity, 79\%) from true progression (mean $K^{\text {trans }}>3.6$; sensitivity, $69 \%$; specificity, $79 \%)$. The increased permeability may confound $K^{\text {trans }}$ because of radiation-induced endothelial damage. Zakhari et $\mathrm{al}^{23}$ reported DSC-derived $\mathrm{rCBV}$ measurement as more accurate than DCE in differentiating TR from RN. They argued against the routine use of DCE perfusion in posttreatment evaluation of HGGs. Seeger et $\mathrm{al}^{25}$ also reported similar results and found better diagnostic performance of rCBV compared with $K^{\text {trans }}$. On the contrary, Shin et al $^{31}$ showed statistically significant differences in $K^{\text {trans }}$ and rCBV and suggested that DCE is more accurate than DSC in posttreatment evaluation of HGGs. Few studies discuss the role of ASL to differentiate TR from posttreatment evaluation of HGGs (On-line Table 1). ${ }^{24-27}$ A meta-analysis identified low diagnostic accuracy of ASL with pooled sensitivity of 52\%-79\% and specificity of $64 \%-82 \% .{ }^{29} \mathrm{Ye} \mathrm{et} \mathrm{al}^{24}$ found a close linear correlation between ASL and DSC PWI in the differentiation of TR from RN. ASL could be an ideal imaging technique for the longterm follow-up of gliomas after treatment, including those with renal dysfunction. ${ }^{24}$

\section{PET with Novel Radiotracers}

PET/CT provides clinically invaluable information about detection, grading, biopsy site selection, and assessing treatment response of tumors. ${ }^{13}$ On-line Table 2 summarizes the various PET radiotracers and their uptake mechanism, half-life, availability, and uptake in the healthy brain. We will discuss the most commonly used FDG, ${ }^{32-37}$ and other various radio-labeled AATs such as ${ }^{11} \mathrm{C}$-MET), ${ }^{32,36,38-42} 6\left[{ }^{18} \mathrm{~F}\right]$ fluoro-L-dopa (FDOPA), ${ }^{43-45}$ and $\left[{ }^{18} \mathrm{~F}\right]$ fluoroethyl-L-tyrosine (FET), ${ }^{46-51}$ as well as ${ }^{18} \mathrm{~F}$-fluorothymidine (FLT), ${ }^{50,52}$ which evaluates DNA syntheses (On-line Table 3).

\section{Glucose Metabolism: FDG-PET}

$\left[{ }^{18} \mathrm{~F}\right]-\mathrm{FDG}$ is a glucose analog that is actively transported into the cells by glucose transporter proteins and phosphorylated to FDG6-phosphate. In cancer cells, increased mitosis, anaerobic glycolysis, glucose transporter proteins level, and glycolytic enzymes contribute to the higher uptake of FDG. Patronas et $\mathrm{al}^{53}$ first, in 1982, used $\left[{ }^{18} \mathrm{~F}\right]-\mathrm{FDG}$ to evaluate posttreatment changes in gliomas. After that, several studies have shown FDG-PET as a useful diagnostic tool to distinguish TR from RN with variable sensitivity $(71 \%-86 \%)$ and specificity $(62 \%-100 \%) .{ }^{32,35-37,43,54,55}$ Gómez-Río et $\mathrm{al}^{37}$ reported higher sensitivity (78\%) and specificity (95\%) of FDG-PET compared with ${ }^{201}$ Tl SPECT in differentiating TR from RN. A meta-analysis including 16 studies reported a pooled sensitivity and specificity of $77 \%$ and $78 \%$, respectively. ${ }^{56}$ Another meta-analysis also confirmed similar results. ${ }^{52}$ Few FDG-PET studies have shown comparable results to MR imaging and suggested that simultaneous PET/MR imaging offers a synergistic multiparametric assessment of recurrence with improved diagnostic accuracy. ${ }^{54,55}$ FDG-PET has inherent limitations of high physiologic uptake in the healthy brain and inflammatory tissue. Hence, the use of various AATs has been proposed. ${ }^{32,33,36,52}$

\section{Amino Acid Transport and Protein Synthesis}

PET with AAT- ${ }^{11} \mathrm{C}-\mathrm{MET},{ }^{32,36,39,40,42}\left[{ }^{18} \mathrm{~F}\right] \mathrm{FET},{ }^{46-50}$ and $\left[{ }^{18} \mathrm{~F}\right]$ FDOPA $^{33,43-45}$ has shown remarkable results in evaluating posttreatment changes of gliomas. Radiolabeled AATs show high tumor-to-background ratio (TBR) in gliomas because of increased cell proliferation and extracellular matrix production.

${ }^{11} \mathrm{C}$-MET is the most studied and validated AAT. Several studies have reported variable sensitivities (66\%-91\%) and specificities $(60 \%-100 \%)$ to differentiate between TR and $\mathrm{RN}^{32,36,39-42}$ Semiquantitative analysis of ${ }^{11} \mathrm{C}$-MET provided an early diagnosis with high diagnostic accuracy even for small lesions. ${ }^{41}$ Qualitative visual interpretation of the images has also shown adequate results for the TR diagnosis. ${ }^{40} \mathrm{~A}$ meta-analysis of ${ }^{11} \mathrm{C}$ MET, including 7 studies, reported a pooled sensitivity of $70 \%$ and specificity of $93 \%$ for detection of recurrence in HGGs. ${ }^{56}$ ${ }^{11} \mathrm{C}-\mathrm{MET}$-PET has shown good correlation with MR imaging, and simultaneous PET/MR imaging could achieve higher diagnostic accuracy. ${ }^{38,39}$

FET-PET has been also reported to be reliable in differentiating posttherapeutic benign changes from TR. ${ }^{46,47}$ FET-PET has shown diagnostic performance similar to FLT and ${ }^{11} \mathrm{C}-\mathrm{MET} .49,50$ In a meta-analysis, $\left[{ }^{18} \mathrm{~F}\right]$ FET had good diagnostic accuracy in differentiating TR from RN with pooled sensitivity and specificity of $82 \%$ and $80 \%$, respectively. ${ }^{57}$ In a recent systematic review, $\left[{ }^{18} \mathrm{~F}\right]$ FET reported better diagnostic performance than FDG and ${ }^{11} \mathrm{C}$ MET. $^{58}$

$\left[{ }^{18} \mathrm{~F}\right] \mathrm{FDOPA}$ is an ideal radiotracer with a longer half-life that shows high uptake in gliomas with low background signal. A number of studies have shown better results with $\left[{ }^{18} \mathrm{~F}\right] \mathrm{FDOPA}$ in evaluating posttreatment changes in gliomas (On-line Table 3). FDOPA-PET has shown superior diagnostic performance (sensitivity, specificity, and accuracy of $100 \%, 85.7 \%$, and $96.4 \%$, respectively) compared with FDG (sensitivity, specificity, and accuracy of $47.6 \%, 100 \%$, and $60.7 \%$, respectively) in differentiating TR from $\mathrm{RN}^{33}$ In a recent meta-analysis of 48 studies, $\left[{ }^{18} \mathrm{~F}\right]$ FDOPA has shown a significant advantage in the diagnosis of glioma recurrence in comparison with $\left[{ }^{18} \mathrm{~F}\right]$ FET (AUC values, 0.9691 versus $0.9124 ; P=.015$ ), though both exhibited moderate overall accuracy in diagnosing TR from $\mathrm{RN}^{57}$

\section{Cell Proliferation and Membrane Biosynthesis}

Cell proliferation and DNA replication are characteristic of malignant transformation. The pyrimidine analog $3^{\prime}$-deoxy-3'-FLT acts as a marker of tumor proliferation, and its uptake in the brain depends on the BBB permeability, thus providing high tumor-to-background contrast in brain tumors. ${ }^{59}$ PET using FLT is found to be an excellent technique for gliomas, with a reported sensitivity of $83 \%-95 \%$ and specificity of $72 \%-100 \%$ for detecting $\mathrm{TR}^{33,44,45}$ A meta-analysis including 24 studies (799 patients) concluded moderately better accuracy of FLT in comparison with FDG for diagnosing TR. ${ }^{52}$ FLT uptake is a function of the plasma input function and its transport rate across the BBB. Therefore, a kinetic model of $\left[{ }^{18} \mathrm{~F}\right]$ FLT uptake, transport, and metabolism is required to quantify DNA synthesis in tumors. ${ }^{60}$ The assumption 
that $\left[{ }^{18} \mathrm{~F}\right]$ FLT reflects the DNA synthesis may be misleading without a kinetic model. ${ }^{61}$ However, in contrast to the FET, no significant advantage was found for FLT ${ }^{50}$ Choline is a precursor for phosphatidylcholine and other phospholipids biosynthesis, which are essential components of the cell membrane and increases in cell proliferation. ${ }^{62}$ A recent meta-analysis revealed high diagnostic accuracy for the identification of TR from the RN with pooled sensitivity and specificity of $87 \%$ and $82 \%$, respectively. ${ }^{63}$ But the number of patients in these studies was relatively small, so no reliable conclusion could not be drawn.

Apart from visual analysis, various parameters have been developed to evaluate the PET images. TBR is helpful in the primary diagnosis and is of paramount importance in follow-up for the posttreatment response evaluation of tumors. Metabolic tumor volume measurement correlates with the overall survival. Recently, a few studies have also shown the feasibility and the added advantage of dynamic PET over static PET acquisition. ${ }^{48,64}$ For static images, the most commonly used parameters are tumor to normal uptake $(\mathrm{T} / \mathrm{N})$, standardized uptake values, and metabolic tumor volume. Higher $\mathrm{T} / \mathrm{N}$ ratios are found associated with poor prognosis for overall survival and progression-free survival in patients with brain tumors. ${ }^{65}$

Dynamic imaging is increasingly used in PET/CT to evaluate brain tumors. After dynamic acquisition, tumors are delineated by using region of interest or volume of interest on all time frames of the dynamic PET data, and time-activity curves are extracted. Time-activity curves are then categorized by various shapes into different time-activity curve patterns, such as increasing plateau or decreasing uptake. ${ }^{48}$ Other parameters such as maximal TBR and minimal time-to-peak could also be derived. ${ }^{66}$

\section{Combined Use of PET and Perfusion MR Imaging}

We have observed the individual roles of PET and PWI in posttreatment evaluation of gliomas. In this section, we include studies that simultaneously used both modalities (either by using hybrid PET/MR imaging or individual PET and MR imaging) in similar groups of patients to distinguish TR from RN. A total of 14 studies were found, including $\left[{ }^{18} \mathrm{~F}\right] \mathrm{FDG}(n=6),{ }^{54,55,67-70}\left[{ }^{18} \mathrm{~F}\right]$ FET $(n=4),{ }^{51,71-73}{ }^{11} \mathrm{C}-\mathrm{MET}(n=2),{ }^{38,74}$ FDOPA $(n=1),{ }^{75}$ and combined FDG with ${ }^{11} \mathrm{C}-\mathrm{MET}(n=1)^{36}$ (On-line Table 4). Hybrid PET/MR imaging improved the overall diagnostic accuracy either by simultaneously or sequentially acquiring the morphologic and functional information in a single short acquisition time. ${ }^{76}$ Kim et $\mathrm{al}^{36}$ first analyzed the combined use of $\left[{ }^{18} \mathrm{~F}\right] \mathrm{FDG}$, ${ }^{11}$ C-MET-PET, and DSC PWI in a small cohort of 10 HGGs. DSC showed statistically insignificant superior results over PET in distinguishing TR from RN. Subsequently, several studies have reported better diagnostic accuracy by simultaneous use of PET and PWI (On-line Table 4). ${ }^{36,38,51,54,55,67-75}$ In a pilot study of 30 HGGs, ASL provided better results than DSC and FDG in detecting TR. However, DSC provided better spatial resolution with improved sensitivity when predominant TR with superimposed regions of predominant mixed $\mathrm{RN}$ were excluded while ASL sensitivity remained unchanged. ${ }^{54}$ Although DSC is the most commonly used PWI, DCE has also shown promising results. Hatzoglou et $\mathrm{al}^{68}$ validated the superior performance of the DCE imaging over FDG in assessing the TR in a heterogeneous cohort of 53 patients ( 29 gliomas and 24 metastases). DCE (AUC $=0.87$ ) outperformed FDG-PET (AUC $=0.75$ ), and the $\mathrm{Vp}$ ratio alone yielded higher predictive value compared with combination of $K^{\text {trans }}$ and the standard uptake value ratio. ${ }^{68}$ In a recent study by Seligman et $\mathrm{al}^{70}{ }^{70}$ FDG-PET and DCE MR imaging showed comparable accuracy and sensitivity in identifying tumor progression, but DCE MR imaging had better specificity. The authors also found the effect of genetic mutations on perfusion-metabolism mismatch for 11 patients with HGGs. Tumors with receptor tyrosine kinase mutations showed less permeability, and tumors with IDH mutations showed lower FDG avidity. Other mutations (RB, p53, and MGMT) were not associated with any perfusion-metabolism discordance. ${ }^{70}$ The authors concluded that a combination of FDG-PET and DCE MR imaging cutoff parameters provides the best diagnostic utility in distinguishing TR from RN. Both modalities achieved high sensitivities, but DCE MR imaging had better specificity. $^{70}$

Integrated PET/MR imaging simultaneously acquires functional and structural parameters, which might have the potential to impact patient management by timely and accurate recognition of TR. ${ }^{55,71,72}$ AATs show superior contrast to that of FDG because of low uptake in the normal brain tissue. $\left[{ }^{18} \mathrm{~F}\right]$ FET provides valuable information for re-radiation treatment planning of HGGs by differentiating metabolically active tumor from normal brain tissue. ${ }^{66}$ Jena et $\mathrm{al}^{51}$ in their multiple receiver operating characteristic analysis found FET uptake, the Cho/Cr ratio, and rCBVmean to be the most useful parameters to distinguish glioma recurrence from $\mathrm{RN}$. The accuracy of $\mathrm{rCBVmean}$ improved after adding maximal TBR or the Cho/Cr ratio. TBR with the $\mathrm{Cho} / \mathrm{Cr}$ ratio yielded the highest accuracy of $97 \%$. In another retrospective study, a combination of rCBVmean, ADCmean, and Cho/Cr resulted in an AUC of 0.91, and a combination of FDG TBR further increased diagnostic accuracy (AUC > 0.93). ${ }^{55}$ Among all individual parameters, the $\mathrm{Cho} / \mathrm{Cr}$ ratio and $\mathrm{FET}$ or FDG TBRmean were the most significant discriminators for the prediction of recurrence. ${ }^{51,55}$ The same group also demonstrated a moderate positive correlation between the FET uptake and rCBV mean, which mirrored the coupled vascularity and amino acid uptake with endothelial proliferation and mitotic activity of the tumor. The diagnostic accuracy, sensitivity, and specificity for recurrence detection by using all MR imaging parameters were $93.75 \%, 96 \%$, and $85.7 \%$, respectively, which further improved to $96.87 \%, 100 \%$, and $85.7 \%$, respectively, on addition of FET TBR. ${ }^{71}$ Recently, a few studies tested the feasibility of dynamic FET-PET and have shown further improvement in the already remarkable diagnostic accuracy of static PET. ${ }^{48,64,72}$ In a large heterogeneous cohort $(n=124)$ of gliomas with different grades and histologies, Galldiks et $\mathrm{al}^{48}$ found a sensitivity of $93 \%$ and specificity of $100 \%$ in differentiating TR from benign treatmentrelated changes by combining static and dynamic FET-PET. Pyka et $\mathrm{al}^{72}$ performed dynamic FET, PWI, and DWI for glioma recurrence. The accuracy of combined multiparametric analysis was higher (AUC $=-0.89$ ) for recurrent gliomas, especially when high specificity was demanded (AUC for static PET $=0.86$, dynamic PET $=0.73$, DWI $=0.73$, and PWI $=0.70) .{ }^{72}$ TR often occurs in the primary tumor bed. Lundemann et $\mathrm{al}^{77}$ have explored the use of pretreatment FET, FDG-PET, and DCE MR 
imaging parameters to predict recurrence location in posttreatment glioblastoma by using voxel analysis. In TR, voxels showed increased FET uptake and elevated vascular permeability (Ki) and Ve. They suggested that subclinical neovascularization already exists at the time of radiation therapy, which later may manifest as visible TR. ${ }^{77}$

${ }^{11} \mathrm{C}$-MET-PET has proved a useful imaging biomarker for glioma recurrence, with less interobserver variability than FDG. D'Souza et $\mathrm{al}^{74}$ demonstrated the high combined diagnostic performance of ${ }^{11} \mathrm{C}$-MET-PET and DSC PWI in the identification of glioma recurrence in which ${ }^{11} \mathrm{C}$-MET seemed to be more sensitive (95\% versus $84 \%$ ) and DSC more specific (90\% versus $80 \%$ ). Qiao et $\mathrm{al}^{38}$ also reported similar results and increased diagnostic performance in a combined multiparametric evaluation of the ${ }^{11} \mathrm{C}-\mathrm{MET}$ and DSC (AUC $=0.953$; sensitivity $=84 \%$; and specificity $=100 \%) \cdot\left[{ }^{18} \mathrm{~F}\right]$ FDOPA was more sensitive and specific for evaluating TR than FDG-PET, especially low-grade glioma recurrence without striatum involvement. ${ }^{33}$ Volumetric and active metabolic tumor parameters have been seen closely associated with clinical outcomes and overall survival of patients with gliomas. $\left[{ }^{18} \mathrm{~F}\right]$ FDOPA identified larger active metabolic tumor volume with significantly higher TBR than DSC rCBV in recurrent gliomas. Larger tumor volume with FDOPA correlated better with real tumor extent, though no targeted biopsies were obtained to assess the discrepancies. ${ }^{75}$ Similar results have also been identified by using ${ }^{11} \mathrm{C}$-MET-PET compared with contrastenhanced MR imaging. ${ }^{48,74}$

Despite inherent technical and biologic differences between these 2 imaging modalities, several authors have claimed that the diagnostic information provided by amino acid PET is comparable with or even superior to that obtained by PWI and vice versa. ${ }^{65}$ The increasing use of advanced MR imaging techniques and the availability of hybrid PET/MR imaging systems will facilitate the optimal use of both modalities in neuro-oncologic applications. Multiparametric analysis of both modalities may improve the overall diagnostic accuracy in the posttreatment evaluation of gliomas.

\section{Challenges and Future Directions}

Despite the advantages, widespread clinical implementation of PET/MR imaging is still limited because of the availability of integrated PET/MR imaging systems and considerable heterogeneities in methodologies. DSC MR imaging and PET with FDG, ${ }^{11} \mathrm{C}$-MET, or FET are the commonly used imaging methods with good quantitative agreement in posttreatment evaluation of gliomas. Overall, DSC and DCE PWI showed comparable high diagnostic accuracy for TR from RN compared with ASL. ${ }^{28,29}$ PWI has the advantage of being less expensive and less time-consuming because these patients generally undergo follow-up MR imaging. Amino acid PET, with a short half-life such as ${ }^{11} \mathrm{C}$-MET, presents logistic difficulties and requires a local cyclotron. Among the available AATs, no significant differences exist in terms of the tumor-to-background uptake, though variations have been seen in tracer distribution and the time-activity curves of the tracer. However, the number of patients in these studies was too small to show reliable conclusions. Other novel promising PET tracers such as FLT and FDOPA are still under investigation.

Hybrid systems allow simultaneous acquisition of PET with perfusion. However, there are technical challenges such as PET attenuation correction, which affects quantitative reliability and its integration into routine clinical workflow. MR imaging-based approaches on the segmentation of Dixon water and fat separation and ultrashort TE sequences have been reported to be inaccurate for attenuation correction and underestimate the tracer uptake in the brain. The recently developed novel Region specific optimization of continuous linear attenuation coefficients based on UTE (RESOLUTE) method for attenuation correction is a clinically acceptable measure that needs further clinical validation. $^{78}$ Another major problem in hybrid PET/MR imaging is movement artifacts, which compromise both MR imaging and PET image quality. ${ }^{79}$

Technical advancements in PET techniques and the everevolving field of radiopharmaceuticals have opened a new domain in glioma imaging. Apart from the usual qualitative uptake parameters, various novel parameters such as shape and uptake heterogeneity may provide additional information on the biologic profile of tumor. ${ }^{80}$ Furthermore, with the introduction of theranostics, which uses the same radiopharmaceuticals for diagnosis and therapy of tumors, better patient management is anticipated. It is achieved by exchanging the radionuclide, that is, short-lived positron emitter ${ }^{68} \mathrm{Ga}$ used for PET with the longer-lived $\beta$-emitters such as yttrium-90 or lutetium-177 for therapy purposes. Research has shown a possible role of new tracers such as ${ }^{68} \mathrm{Ga}$ PSMA-11, ${ }^{68} \mathrm{Ga}$-labeled peptides (arginylglycylaspartic acid peptides and substance P), and ${ }^{64} \mathrm{Cu}$ chloride in patients with suspected glioma recurrence. $^{81}$

\section{Limitations}

HGG is a relatively rare tumor with a dismal prognosis. Several $\mathrm{PET} / \mathrm{MR}$ imaging studies using multiparametric evaluation have been undertaken to identify glioma recurrences. However, most studies are retrospective, include a limited number of patients, and use heterogeneous imaging protocols and methods. Histopathologic confirmation of the $\mathrm{RN}$ is not available in many patients. In general, most RN diagnoses were established if the lesion remained unchanged or shrank or disappeared on subsequent imaging or clinical follow-up. The PET/MR imaging parameter cutoff values are not standardized. The diagnostic accuracies were variable secondary to the differences in methods, perfusion and PET techniques, radiotracers, and reference standards (histopathology versus clinical follow-up). These limitations need consideration when analyzing the study results.

\section{CONCLUSIONS}

Advanced PET/MR imaging techniques noninvasively examine the biologic properties of the tumor and complement the MR imaging alone. With the available clinical literature, it is apparent that combined use of amino acid PET and perfusion MR imaging improves the overall diagnostic accuracy for earlier detection of recurrence, but more research is needed to identify the most optimal use. Currently, this field is held back by a lack of a clear consensus because of the use of heterogeneous protocols and 
interpretative criteria. Therefore, large prospective, multi-institutional studies using a homogeneous protocol are needed to investigate and validate these results.

Disclosures: Girish Bathla_UNRELATED: Grants/Grants Pending: research grant with Siemens.

\section{REFERENCES}

1. Auffinger B, Thaci B, Nigam P, et al. New therapeutic approaches for malignant glioma: in search of the Rosetta stone. F1000 Med Rep 2012;4:18 CrossRef Medline

2. Roy S, Lahiri D, Maji T, et al. Recurrent glioblastoma: where we stand. South Asian J Cancer 2015;4:163-73 CrossRef Medline

3. Verma N, Cowperthwaite MC, Burnett MG, et al. Differentiating tumor recurrence from treatment necrosis: a review of neuro-oncologic imaging strategies. Neuro-oncology 2013;15:515-34 CrossRef Medline

4. van Dijken BRJ, van Laar PJ, Smits M, et al. Perfusion MRI in treatment evaluation of glioblastomas: clinical relevance of current and future techniques. J Magn Reson Imaging 2019;49:11-22 CrossRef Medline

5. Zikou A, Sioka C, Alexiou GA, et al. Radiation necrosis, pseudoprogression, pseudoresponse, and tumor recurrence: imaging challenges for the evaluation of treated gliomas. Contrast Media Mol Imaging 2018;2018:6828396 CrossRef Medline

6. Abbasi AW, Westerlaan HE, Holtman GA, et al. Incidence of tumour progression and pseudoprogression in high-grade gliomas: a systematic review and meta-analysis. Clin Neuroradiol 2018; 28:401-11 CrossRef Medline

7. Bahrami N, Piccioni D, Karunamuni R, et al. Edge contrast of the FLAIR hyperintense region predicts survival in patients with highgrade gliomas following treatment with bevacizumab. AJNR Am J Neuroradiol 2018;39:1017-24 CrossRef Medline

8. Verger A, Arbizu J, Law I. Role of amino-acid PET in high-grade gliomas: limitations and perspectives. Q J Nucl Med Mol Imaging 2018;62:254-66 CrossRef Medline

9. Kreth F, Muacevic A, Medele R, et al. The risk of haemorrhage after image guided stereotactic biopsy of intra-axial brain tumours: a prospective study. Acta Neurochir (Wien) 2001;143:539-46 CrossRef Medline

10. Gallego O. Nonsurgical treatment of recurrent glioblastoma. Curr Oncol 2015;22:e273-81 CrossRef Medline

11. Essig M, Shiroishi MS, Nguyen TB, et al. Perfusion MRI: the five most frequently asked technical questions. AJR Am J Roentgenol 2013;200:24-34 CrossRef Medline

12. Welker K, Boxerman J, Kalnin A, et al. ASFNR recommendations for clinical performance of MR dynamic susceptibility contrast perfusion imaging of the brain. AJNR Am J Neuroradiol 2015;36: E41-51 CrossRef Medline

13. la Fougère C, Suchorska B, Bartenstein $P$, et al. Molecular imaging of gliomas with PET: opportunities and limitations. Neuro Oncol 2011;13:806-19 CrossRef Medline

14. Barajas RF, Jr., Chang JS, Segal MR, et al. Differentiation of recurrent glioblastoma multiforme from radiation necrosis after external beam radiation therapy with dynamic susceptibility-weighted contrast-enhanced perfusion MR imaging. Radiology 2009;253:48696 CrossRef Medline

15. Young RJ, Gupta A, Shah AD, et al. MRI perfusion in determining pseudoprogression in patients with glioblastoma. Clin Imaging 2013;37:41-49 CrossRef Medline

16. Di Costanzo A, Scarabino T, Trojsi F, et al. Recurrent glioblastoma multiforme versus radiation injury: a multiparametric 3-T MR approach. Radiol Med 2014;119:616-24 CrossRef Medline

17. Prager AJ, Martinez N, Beal K, et al. Diffusion and perfusion MRI to differentiate treatment-related changes including pseudoprogression from recurrent tumors in high-grade gliomas with histopathologic evidence. AJNR Am J Neuroradiol 2015;36:877-85 CrossRef Medline

18. Wang S, Martinez-Lage M, Sakai Y, et al. Differentiating tumor progression from pseudoprogression in patients with glioblastomas using diffusion tensor imaging and dynamic susceptibility contrast MRI. AJNR Am J Neuroradiol 2016;37:28-36 CrossRef Medline

19. Blasel S, Zagorcic A, Jurcoane A, et al. Perfusion MRI in the evaluation of suspected glioblastoma recurrence. J Neuroimaging 2016; 26:116-23 CrossRef Medline

20. Thomas AA, Arevalo-Perez J, Kaley T, et al. Dynamic contrast enhanced T1 MRI perfusion differentiates pseudoprogression from recurrent glioblastoma. J Neurooncol 2015;125:183-90 CrossRef Medline

21. Yun TJ, Park CK, Kim TM, et al. Glioblastoma treated with concurrent radiation therapy and temozolomide chemotherapy: differentiation of true progression from pseudoprogression with quantitative dynamic contrast-enhanced MR imaging. Radiology 2015;274:830-40 CrossRef Medline

22. Nael K, Bauer AH, Hormigo A, et al. Multiparametric MRI for differentiation of radiation necrosis from recurrent tumor in patients with treated glioblastoma. AJR Am J Roentgenol 2018;210:18-23 CrossRef Medline

23. Zakhari N, Taccone MS, Torres $\mathrm{CH}$, et al. Prospective comparative diagnostic accuracy evaluation of dynamic contrast-enhanced (DCE) vs. dynamic susceptibility contrast (DSC) MR perfusion in differentiating tumor recurrence from radiation necrosis in treated high-grade gliomas. J Magn Reson Imaging 2019;50:573-82 CrossRef Medline

24. Ye J, Bhagat SK, Li H, et al. Differentiation between recurrent gliomas and radiation necrosis using arterial spin labeling perfusion imaging. Exp Ther Med 2016;11:2432-36 CrossRef Medline

25. Seeger A, Braun C, Skardelly M, et al. Comparison of three different MR perfusion techniques and MR spectroscopy for multiparametric assessment in distinguishing recurrent high-grade gliomas from stable disease. Acad Radiology 2013;20:1557-65 CrossRef Medline

26. Nyberg E, Honce J, Kleinschmidt-DeMasters BK, et al. Arterial spin labeling: pathologically proven superiority over conventional MRI for detection of high-grade glioma progression after treatment. Neuroradiol J 2016;29:377-83 CrossRef Medline

27. Razek A, El-Serougy L, Abdelsalam M, et al. Differentiation of residual/recurrent gliomas from postradiation necrosis with arterial spin labeling and diffusion tensor magnetic resonance imagingderived metrics. Neuroradiology 2018;60:169-77 CrossRef Medline

28. Patel P, Baradaran H, Delgado D, et al. MR perfusion-weighted imaging in the evaluation of high-grade gliomas after treatment: a systematic review and meta-analysis. Neuro Oncol 2017;19:118-27 CrossRef Medline

29. van Dijken BRJ, van Laar PJ, Holtman GA, et al. Diagnostic accuracy of magnetic resonance imaging techniques for treatment response evaluation in patients with high-grade glioma, a systematic review and meta-analysis. Eur Radiology 2017;27:4129-44 CrossRef Medline

30. Kim HS, Goh MJ, Kim N, et al. Which combination of MR imaging modalities is best for predicting recurrent glioblastoma? Study of diagnostic accuracy and reproducibility. Radiology 2014;273:831-43 CrossRef Medline

31. Shin KE, Ahn KJ, Choi HS, et al. DCE and DSC MR perfusion imaging in the differentiation of recurrent tumour from treatmentrelated changes in patients with glioma. Clin Radiol 2014;69:e26472 CrossRef Medline

32. Takenaka S, Asano Y, Shinoda J, et al. Comparison of (11)C-methionine, (11)C-choline, and (18)F-fluorodeoxyglucose-PET for distinguishing glioma recurrence from radiation necrosis. Neurol Med Chir(Tokyo) 2014;54:280-89 CrossRef Medline

33. Karunanithi S, Sharma P, Kumar A, et al. 18F-FDOPA PET/CT for detection of recurrence in patients with glioma: prospective 
comparison with 18F-FDG PET/CT. Eur J Nucl Med Mol Imaging 2013;40:1025-35 CrossRef Medline

34. Santra A, Kumar R, Sharma P, et al. F-18 FDG PET-CT in patients with recurrent glioma: comparison with contrast enhanced MRI. Eur J Radiology 2012;81:508-13 CrossRef Medline

35. Tan H, Chen L, Guan Y, et al. Comparison of MRI, F-18 FDG, and 11C-choline PET/CT for their potentials in differentiating brain tumor recurrence from brain tumor necrosis following radiotherapy. Clin Nucl Med 2011;36:978-81CrossRef Medline

36. Kim YH, Oh SW, Lim YJ, et al. Differentiating radiation necrosis from tumor recurrence in high-grade gliomas: assessing the efficacy of 18F-FDG PET, 11C-methionine PET and perfusion MRI. Clin Neurol Neurosurg 2010;112:758-65 CrossRef Medline

37. Gómez-Río M, Rodríguez-Fernández A, Ramos-Font $\mathrm{C}$, et al. Diagnostic accuracy of 201Thallium-SPECT and 18F-FDG-PET in the clinical assessment of glioma recurrence. Eur J Nucl Med Mol Imaging 2008;35:966-75 CrossRef Medline

38. Qiao Z, Zhao X, Wang K, et al. Utility of dynamic susceptibility contrast perfusion-weighted $\mathrm{MR}$ imaging and (11)C-methionine PET/CT for differentiation of tumor recurrence from radiation injury in patients with high-grade gliomas. AJNR Am J Neuroradiol 2019;40:253-59 CrossRef Medline

39. Deuschl C, Kirchner J, Poeppel TD, et al. 11C-MET PET/MRI for detection of recurrent glioma. Eur J Nucl Med Mol Imaging 2018; 45:593-601 CrossRef Medline

40. Minamimoto R, Saginoya T, Kondo C, et al. Differentiation of brain tumor recurrence from post-radiotherapy necrosis with $11 \mathrm{C}$-methionine PET: visual assessment versus quantitative assessment. PLoS One 2015; 10:e0132515 CrossRef Medline

41. Okamoto S, Shiga T, Hattori N, et al. Semiquantitative analysis of C-11 methionine PET may distinguish brain tumor recurrence from radiation necrosis even in small lesions. Ann Nucl Med 2011;25:213-20 CrossRef Medline

42. Terakawa Y, Tsuyuguchi N, Iwai Y, et al. Diagnostic accuracy of 11C-methionine PET for differentiation of recurrent brain tumors from radiation necrosis after radiotherapy. J Nucl Med 2008;49: 694-99 CrossRef Medline

43. Karunanithi S, Sharma P, Kumar A, et al. Comparative diagnostic accuracy of contrast-enhanced MRI and 18F-FDOPA PET-CT in recurrent glioma. Eur Radiol 2013;23:2628-35 CrossRef Medline

44. Rossi Espagnet MC, Romano A, Mancuso V, et al. Multiparametric evaluation of low grade gliomas at follow-up: comparison between diffusion and perfusion MR with (18)F-FDOPA PET. Br J Radiol 2016;89:20160476 CrossRef Medline

45. Herrmann K, Czernin J, Cloughesy T, et al. Comparison of visual and semiquantitative analysis of 18F-FDOPA-PET/CT for recurrence detection in glioblastoma patients. Neuro-Oncology 2014;16: 603-09 CrossRef Medline

46. Rachinger W, Goetz C, Pöpperl G, et al. Positron emission tomography with $\mathrm{O}-(2-[18 \mathrm{~F}]$ fluoroethyl)-1-tyrosine versus magnetic resonance imaging in the diagnosis of recurrent gliomas. Neurosurgery 2005;57:505-11; discussion 505-11 CrossRef Medline

47. Pöpperl G, Götz C, Rachinger W, et al. Value of O-(2-[18F]fluoroethyl)- L-tyrosine PET for the diagnosis of recurrent glioma. Eur J Nucl Med Mol Imaging 2004;31:1464-70 CrossRef Medline

48. Galldiks N, Stoffels G, Filss C, et al. The use of dynamic O-(2-18Ffluoroethyl)-l-tyrosine PET in the diagnosis of patients with progressive and recurrent glioma. Neuro-Oncology 2015;17:1293-1300 CrossRef Medline

49. Grosu A-L, Astner ST, Riedel E, et al. An interindividual comparison of O-(2-[18F]fluoroethyl)-L-tyrosine (FET)- and L-[methyl11C]methionine (MET)-PET in patients with brain gliomas and metastases. Int J Radiat Oncol Biol Phys 2011;81:1049-58 CrossRef Medline

50. Jeong SY, Lee TH, Rhee CH, et al. $\mathbf{3}^{\prime}$-Deoxy-3'-[18F]fluorothymidine and $\mathrm{O}-(2-[18 \mathrm{~F}]$ fluoroethyl)-L-tyrosine PET in patients with suspicious recurrence of glioma after multimodal treatment: initial results of a retrospective comparative study. $\mathrm{Nucl} \mathrm{Med} \mathrm{Mol}$ Imaging 2010;44:45-54 CrossRef Medline

51. Jena A, Taneja S, Gambhir A, et al. Glioma recurrence versus radiation necrosis: single-session multiparametric approach using simultaneous O-(2-18F-fluoroethyl)-L-tyrosine PET/MRI. Clin Nucl Med 2016;41:e228-36 CrossRef Medline

52. Li Z, Yu Y, Zhang H, et al. A meta-analysis comparing 18F-FLT PET with 18F-FDG PET for assessment of brain tumor recurrence. Nucl Med Commun 2015;36:695-701 CrossRef Medline

53. Patronas N, Di Chiro G, Brooks R, et al. Work in progress: [18F] fluorodeoxyglucose and positron emission tomography in the evaluation of radiation necrosis of the brain. Radiology 1982;144:885-89 CrossRef Medline

54. Ozsunar Y, Mullins ME, Kwong K, et al. Glioma recurrence versus radiation necrosis? A pilot comparison of arterial spin-labeled, dynamic susceptibility contrast enhanced MRI, and FDG-PET imaging. Acad Radiol 2010;17:282-90 CrossRef Medline

55. Jena A, Taneja S, Jha A, et al. Multiparametric evaluation in differentiating glioma recurrence from treatment-induced necrosis using simultaneous (18)F-FDG-PET/MRI: a single-institution retrospective study. AJNR Am J Neuroradiol 2017;38:899-907 CrossRef Medline

56. Nihashi T, Dahabreh IJ, Terasawa T. Diagnostic accuracy of PET for recurrent glioma diagnosis: a meta-analysis. AJNR $A m J$ Neuroradiol 2013;34:944-950 CrossRef Medline

57. Yu J, Zheng J, Xu W, et al. Accuracy of (18)F-FDOPA positron emission tomography and (18)F-FET positron emission tomography for differentiating radiation necrosis from brain tumor recurrence. World Neurosurg 2018;114:e1211-24 CrossRef Medline

58. Furuse M, Nonoguchi N, Yamada K, et al. Radiological diagnosis of brain radiation necrosis after cranial irradiation for brain tumor: a systematic review. Radiat Oncol 2019;14:28 CrossRef Medline

59. Herholz K. Brain tumors: an update on clinical PET research in gliomas. Semin Nucl Med 2017;47:5-17 CrossRef Medline

60. Ullrich R, Backes $\mathrm{H}, \mathrm{Li} \mathrm{H}$, et al. Glioma proliferation as assessed by 3'-fluoro-3'-deoxy-L-thymidine positron emission tomography in patients with newly diagnosed high-grade glioma. Clin Cancer Res 2008;14:2049-55 CrossRef Medline

61. Peck M, Pollack HA, Friesen A, et al. Applications of PET imaging with the proliferation marker [18F]-FLT. Q J Nucl Med Mol Imaging 2015;59:95-104 Medline

62. Zeisel SH. Dietary choline: biochemistry, physiology, and pharmacology. Annu Rev Nutr 1981;1:95-121 CrossRef Medline

63. Gao L, Xu W, Li T, et al. Accuracy of 11C-choline positron emission tomography in differentiating glioma recurrence from radiation necrosis: a systematic review and meta-analysis. Medicine (Baltimore) 2018;97:e11556 CrossRef Medline

64. Pyka T, Gempt J, Ringel F, et al. Prediction of glioma recurrence using dynamic ${ }^{18}$ F-fluoroethyltyrosine PET. AJNR Am J Neuroradiol 2014;35:1924-29 CrossRef Medline

65. Zhang Q, Gao X, Wei G, et al. Prognostic value of MTV, SUVmax and the $\mathrm{T} / \mathrm{N}$ ratio of $\mathrm{PET} / \mathrm{CT}$ in patients with glioma: a systematic review and meta-analysis. J Cancer 2019;10:1707-16 CrossRef Medline

66. Fleischmann DF, Unterrainer M, Corradini S, et al. Report of first recurrent glioma patients examined with PET-MRI prior to reirradiation. PLoS One 2019; 14:e0216111 CrossRef Medline

67. Prat $\mathrm{R}$, Galeano I, Lucas A, et al. Relative value of magnetic resonance spectroscopy, magnetic resonance perfusion, and $2-(18 \mathrm{~F})$ fluoro-2-deoxy-D-glucose positron emission tomography for detection of recurrence or grade increase in gliomas. $J$ Clin Neurosci 2010;17:50-53 CrossRef Medline

68. Hatzoglou V, Yang TJ, Omuro A, et al. A prospective trial of dynamic contrast-enhanced MRI perfusion and fluorine-18 FDG PET-CT in differentiating brain tumor progression from radiation injury after cranial irradiation. Neuro Oncol 2016;18:873-80 CrossRef Medline 
69. Hojjati M, Badve C, Garg V, et al. Role of FDG-PET/MRI, FDGPET/CT, and dynamic susceptibility contrast perfusion MRI in differentiating radiation necrosis from tumor recurrence in glioblastomas. J Neuroimaging 2018;28:118-25 CrossRef Medline

70. Seligman L, Kovanlikaya I, Pisapia DJ, et al. Integrated PET-MRI for glioma surveillance: perfusion-metabolism discordance rate and association with molecular profiling. AJR Am J Roentgenol 2019; 212:883-91 CrossRef Medline

71. Sogani SK, Jena A, Taneja S, et al. Potential for differentiation of glioma recurrence from radionecrosis using integrated (18)F-fluoroethyl-L-tyrosine (FET) positron emission tomography/magnetic resonance imaging: a prospective evaluation. Neurol India 2017; 65:293-301 CrossRef Medline

72. Pyka T, Hiob D, Preibisch C, et al. Diagnosis of glioma recurrence using multiparametric dynamic 18F-fluoroethyl-tyrosine PETMRI. Eur J Radiol 2018;103:32-37 CrossRef Medline

73. Verger A, Filss CP, Lohmann P, et al. Comparison of O-(2-(18)FFluoroethyl)-L-tyrosine positron emission tomography and perfusion-weighted magnetic resonance imaging in the diagnosis of patients with progressive and recurrent glioma: a hybrid positron emission tomography/magnetic resonance study. World Neurosurg 2018;113:e727-37 CrossRef Medline

74. D'Souza MM, Sharma R, Jaimini A, et al. 11C-MET PET/CT and advanced MRI in the evaluation of tumor recurrence in high-grade gliomas. Clin Nucl Med 2014;39:791-98 CrossRef Medline
75. Cicone F, Filss CP, Minniti G, et al. Volumetric assessment of recurrent or progressive gliomas: comparison between F-DOPA PET and perfusion-weighted MRI. Eur J Nucl Med Mol Imaging 2015;42:905-15 CrossRef Medline

76. Yang Y, He MZ, Li T, et al. MRI combined with PET-CT of different tracers to improve the accuracy of glioma diagnosis: a systematic review and meta-analysis. Neurosurg Rev 2019;42: 185-95 CrossRef Medline

77. Lundemann M, Munck Af Rosenschold P, Muhic A, et al. Feasibility of multi-parametric PET and MRI for prediction of tumour recurrence in patients with glioblastoma. Eur J Nucl Med Mol Imaging 2019;46:603-13 CrossRef Medline

78. Ladefoged CN, Andersen FL, Kjaer A, et al. RESOLUTE PET/MRI attenuation correction for $\mathrm{O}-(2-(18) \mathrm{F}-$ fluoroethyl)-L-tyrosine (FET) in brain tumor patients with metal implants. Front Neurosci 2017;11:453 CrossRef Medline

79. Marner L, Henriksen OM, Lundemann M, et al. Clinical PET/MRI in neurooncology: opportunities and challenges from a singleinstitution perspective. Clin Transl Imaging 2017;5:135-49 CrossRef Medline

80. Jung JH, Ahn BC. Current radiopharmaceuticals for positron emission tomography of brain tumors. Brain Tumor Res Treat 2018;6: 47-53 CrossRef Medline

81. Bailly C, Vidal A, Bonnemaire C, et al. Potential for nuclear medicine therapy for glioblastoma treatment. Front Pharmacol 2019;10: 772-72 CrossRef Medline 